\title{
Internet Technologies as Pedagogical Condition for Forming Foreign Language Skills of Content Teachers (at Technical University)
}

\author{
Inga V. Slesarenko, $\mathrm{PhD}$, assistant professor ${ }^{1}$ \\ Irina K. Zabrodina, $\mathrm{PhD}$, assistant professor ${ }^{2}$ \\ ${ }^{1}$ National Research Tomsk Polytechnic University \\ ${ }^{2}$ National Research Tomsk Polytechnic University
}

\begin{abstract}
The paper addresses the issue of communicative competence developing using Internet technologies as an important aspect of professional competence for cooperative learning of technical university content teachers. The discussed algorithm is based on five pedagogical conditions for forming foreign language skills of Content Teachers' (at Technical University) by means of modern Internettechnologies.
\end{abstract}

Keywords: Internet technologies; pedagogical conditions; cooperative learning pedagogy; forming foreign language skills of Content Teachers'

\section{Introduction}

Technical university internationalization processes brought to understanding of engineering skills and competences as universal markers of what a professional engineer to be for in global market.

Knowledge of several foreign languages comes in such case as a necessity accompanied by circumstances of globalization processes, tighter bounds with international industries throughout the globe and labor force migration through countries. The problem of educating of engineers with the valuable set of forthcoming skills and competences that would allow them successfully integrate into rapidly changing society, industry and economics throughout the world has been continually discussed in for more than a decade [1].

The main challenge for Russian engineering education right now is to train competitive specialists, engineers with set of skills and scope of professional competences that would satisfy industry demands and be recognized worldwide. Integration into world engineering education and labor market transfers engineering educational programs into internationalized making foreign language skills a must for future engineers' career success.

An important aspect of professional competence communicative competence in foreign languages has modified dramatically according to the needs claimed, thus profession-oriented training in foreign languages is to replace academic-oriented one. The article represents the experience of National Research Tomsk Polytechnic University, Russia, in foreign language training for content teachers of technical disciplines.
Language environment in Russian university as a phenomenon is not so far intensively studied or discussed. Meanwhile language environment in Russian technical university plays more than a significant role in success of international collaboration activities. More often managerial dimensions of internationalization of technical universities come into focus. In other words the questions to be put and answered are the following: what internalization goals are and by what managerial expenses in terms of labor, cost and organizational structures a university are to achieve them. Such internalization goals are presented in the Development Program of Tomsk Polytechnic University (TPU) [2]. Among them are the following:

- Functioning of international research laboratories at TPU

- Attracting and teaching international students

- Scientific publications on Web of Science, Scopus

- Professional enhancement courses abroad, etc.

In order for these activities to be performed professionals with advanced foreign language skills are required by modern Russian technical university.

\section{TPU foreign language training system}

Foreign language training system implemented at TPU has modified dramatically according to the needs of modern education and training specialists, industry demands in highly competitive specialists.

These specialists are able to read manuals and instructions in foreign languages, can participate in collaborative international activities, perform engineering innovative tasks in a foreign language and communicate their ideas to professionals in the field as well as to general public.

The challenges here are envisioned were discussed in the previous papers and are as the following:

- Intensity of foreign language training compressed by classroom hours devoted to foreign language studies

- Necessity to design online courses for independent studies

- Different formats of foreign language learning and acquisition including immersion programs

- The necessity of designing foreign language training programs for all university population: from students to their teachers and professors, as well as 
for other employee categories - administrative personnel and top management.

The above challenges are reflected in activities aimed to overcome them. The given below examples of activities within TPU goals of development are stated in TPU Competitiveness Enhancement Programme among them document processing in foreign language, participation in international research teams, lecturing for international students, international conference participation and scientific paper writing.

One of the main challenges in foreign language training at TPU is to redesign it from the academic oriented to profession oriented one [3]. Within the stains of the above mentioned pedagogical conditions of foreign language learning modern Internet technologies applied in educational process play significant role in terms of learning process structuring and organization, providing individual pace to learners and new functions to foreign language instructors.

\section{The consequence of pedagogical conditions for forming foreign language skills by means of mod- ern Internet-technologies}

The forming foreign language skills of Content Teachers (at Technical University) by means of modern Internet-technologies can be successful, if the pedagogical conditions are taken into account. In this paper many factors studied by scientists have been put into groups.

The first pedagogical condition forming foreign language skills by means of modern Internet-technologies is the evolving teachers' ICT-competence as of the beginning of within-post career development process. There are many concepts in scientific literature being close in their meaning to the term ICT-competence (competence in the sphere of information and communication technologies). In accordance with the works of S. Savignon and P. Sysoyev, ICT competence is defined as "the ability to use a wide range of information and communication technologies in the process of teaching a foreign language and its culture" [4].

Many Russian and foreign scientists put up a question concerning the distinguish ability of the development of course participant' ICT-competence as a pedagogical condition of elaboration and implementation of the methods of teaching a foreign language and its culture by means of modern Internet-technologies.

Evolving ICT-competence of teachers, training for within-post career development, includes knowledge and skills in using blog-technologies, wiki-technologies, services of podcast for information exchange, synchronous and asynchronous communication, creating and discussing the educational content based on them.

Course participants demonstrating lack of knowledge and skills of ICT-competence are unable to be completely involved in class work on Internet-project implementation. In this respect evolving students' ICT-competence is regarded as the first pedagogical condition for forming foreign language skills by means of modern Internettechnologies.
Methods of teaching a foreign language and culture by means of Internet-technologies have been elaborated and described in many recent pedagogical works. As the analysis of these works shows, every used Internetservice and Internet-technology has its didactic characteristics and functions. Didactic characteristics of modern ICT-technologies, the main qualities, features of the particular technologies distinguishing one technology from another, are essential for didactics in the plane of theory as well as practice.

Didactic functions are defined as external manifestation of ICT means, used in educational process for the realization of the set goals. In particular, blog-technology can be characterized as available to all Internet-users, having linear sequence of upcoming messages and allowing using multi-media. In this technology the author and the moderator is one and the same person [5]. It is obvious that methods of teaching aspects of a language, types of speech and culture based on the particular Internettechnologies are different due to varieties in didactic characteristics and functions in different Internettechnologies. For instance, wiki-technology enables students to create a common piece of writing while blogtechnology enables students to create individual (notgroup) writing.

It is essential to take into account didactic characteristics and functions of every particular Internet-technology for the elaboration of a particular method and particular educational task solution. In this respect the second pedagogical condition for forming foreign language skills of Content Teachers (at Technical University) by means of modern Internet-technologies is consideration of the didactic characteristics and ICT function peculiarities [6]

In many research works devoted to the usage of Internet-technologies in foreign language teaching the importance to develop students' skills in team work in the process of particular tasks solution is mentioned. Most Internet projects require students' interaction in the process of common writing creation and its discussion. In scientific papers it was reflected in the pedagogical technology called "cooperative learning". Theoretical groundwork of this pedagogical technology was laid by American pedagogical worker John Dewey [7]. Among different methods of teaching a foreign language the method of "cooperative learning" has become a frequent practice due to his works.

One of the conditions of the technology implementation is the interdependence of the participants of the joint educational activity. The implementation of cooperative learning is based on the following common principles:

- The participants' course is formed in the way that there are participants with different level of language proficiency, different experience in joint educational activities, different sex and etc. Such kind of group formation creates conditions for every team member to develop necessary skills in the process of conjoint project implementation 
- Each group is given tasks according to which every member gets a special role in order to be involved in the activity

- Each group is given a series of tasks (a text, a series of exercises, an Internet-site where the project should be carried out)

- Members of the group are given common points.

The peculiarity of the pedagogical technology "cooperative learning" is that in the process of task implementation every participant is responsible for his part of work as well as the whole project. Ultimately, not the individual work of every member of the group is assessed but the result of their co-operation. As a result, the given technology enables team members to communicate and collaborate in order to succeed in joint working.

In this regard the use of the pedagogical technology "cooperative learning" in the process of Internet-project realization is supposed to be the third pedagogical condition forming foreign language skills of Content Teachers (at Technical University) via modern Internettechnologies.

Three main types of assignments are distinguished: 1) searching and playing 2) cognitive-searching and 3) cognitive-researching [8].

Due to cognitive and communicative students' abilities cognitive-searching as well as educational-researching assignments, tasks and projects devoted to culture study can be put to use.

All these kinds of assignments are used to support objectives of students' education in the sphere of culture study by means of a foreign language: multidisciplinary bilingual and multicultural education of course participants by means of their mother tongue and a foreign language; development of multifunctional competence including ideas of co-studied cultural communities and cross-cultural communication skills allowing to overcome information gaps or culture conflicts coming in contact with unfamiliar cultures; development of analyzing skills, classification and systemization, grouping and other material dedicated to culture study; development of skills in native culture description; teaching technologies of cultural discrimination and cultural aggression resistance, cultural vandalism resistance; arrangement conditions for creative work.

In the course of implementation and use of cognitivesearching assignments developing students' multidisciplinary and foreign communicative competence after a while students will be able to carry out more complicated educational projects dedicated to culture study. Therefore problem-solving assignments devoted to culture study are regarded as the forth pedagogical condition for forming foreign language skills of Content Teachers (at Technical University) by means of modern Internet-technologies.

In addition, it is very important to devise a training algorithm where teacher and course participants' functions are given in details at every stage of their activity. It can enable students to be aware of educational teamwork procedure in the course of working on Internet-project. If this is not the case, they would not pay enough attention or completely ignore particular aspects of a language.

\section{Conclusion}

In the paper was proved scientifically that the forming foreign language skills of Content Teachers' (at Technical University) by means of modern Internettechnologies is a success only in the light of the foregoing pedagogical conditions.

Knowledge and proficiency in foreign language plays a significant role in Russian engineering university internationalization processes. It allows students, teachers and professors, other employees' categories - administrative staff and top management actively to participate in all internationally related activities such as academic exchanges, international research and collaboration, teaching and hosting international students in friendly environment, turning a university into a more attractive place for work and studies.

The next step will be to incorporate Internet based technologies not only in language teaching but foster foreign language environment development within the University through media and communications.

\section{Acknowledgements}

"This work is funded within the framework of realization of Strategic Programme on National Research Tomsk Polytechnic University Competitiveness Enhancement in the Group of Top Level World Research and Academic Institutions".

\section{References}

[1] T. Birand, "Engieering Tomorrow`s Engineers," Global Journal of Engineering Education, pp. 65-71, 2006.

[2] TPU Competitiveness Enhancement Programme http://tpu.ru/en/about/plans.

[3] I.V. Slesarenko, "Profession-oriented Foreign Language Training in Russian Technical University," 40th IGIP International Symposium on Engineering Education, COPEC, pp. 1351-1354, 2011.

[4] S. Savignon, and P. Sysoyev, "Sociocultural strategies for Dialogue of Cultures," The Modern Language Journal No 86(4), pp. 508-524, 2002.

[5] I.K. Zabrodina, "The analysis of blog-technology didactic features and functions by developing a sociocultural competence of students," Philological Sciences. Theoriy and Practice Iissues No 11-2, pp. 98$101,2013$.

[6] J. Oelkers, "John Dewey and Pedagogic," 2009.

[7] M. Klink, "The use of interaction methods in a blended learning environment," Essay (Master), 2006.

[8] K. Debevec, M. Shih, and V. Kashyap, "Learning strategies and performance in a technology-integrated classroom," Journal of Research on Technology in Education No 38, pp. 293-307, 2006. 